Published in final edited form as:

Subcell Biochem. 2018 ; 87: 141-165. doi:10.1007/978-981-10-7757-9_6.

\title{
Transient Receptor Potential (TRP) Channels
}

\author{
Amrita Samanta, \\ Department of Pharmacology, School of Medicine, Case Western Reserve University, Cleveland, \\ $\mathrm{OH}, \mathrm{USA}$ \\ Department of Physiology and Biophysics School of Medicine, Case Western Reserve University, \\ Cleveland, $\mathrm{OH}, \mathrm{USA}$ \\ Taylor E. T. Hughes, and \\ Department of Pharmacology, School of Medicine, Case Western Reserve University, Cleveland, \\ $\mathrm{OH}, \mathrm{USA}$ \\ Vera Y. Moiseenkova-Bell \\ Department of Pharmacology, School of Medicine, Case Western Reserve University, Cleveland, \\ $\mathrm{OH}, \mathrm{USA}$ \\ Department of Physiology and Biophysics School of Medicine, Case Western Reserve University, \\ Cleveland, $\mathrm{OH}, \mathrm{USA}$
}

\section{Abstract}

Transient Receptor Potential (TRP) channels are evolutionarily conserved integral membrane proteins. The mammalian TRP superfamily of ion channels consists of 28 cation permeable channels that are grouped into six subfamilies based on sequence homology (Fig. 6.1). The canonical TRP (TRPC) subfamily is known for containing the founding member of mammalian TRP channels. The vanilloid TRP (TRPV) subfamily has been extensively studied due to the heat sensitivity of its founding member. The melastatin-related TRP (TRPM) subfamily includes some of the few known bi-functional ion channels, which contain functional enzymatic domains. The ankyrin TRP (TRPA) subfamily consists of a single chemo-nociceptor that has been proposed to be a target for analgesics. The mucolipin TRP (TRPML) subfamily channels are found primarily in intracellular compartments and were discovered based on their critical role in type IV mucolipidosis (ML-IV). The polycystic TRP (TRPP) subfamily is a diverse group of proteins implicated in autosomal dominant polycystic kidney disease (ADPKD). Overall, this superfamily of channels is involved in a vast array of physiological and pathophysiological processes making the study of these channels imperative to our understanding of subcellular biochemistry.

\section{Keywords}

Transient receptor potential channels; TRPC; TRPV; TRPM; TRPA; TRPML; TRPP; Cryoelectron microscopy; Thermosensation; PKD1; PKD2; Polycystin 


\subsection{Introduction}

In order to survive, organisms have adapted to rapidly and accurately sense the environment around them. One group of biomolecules that play a key role in interpreting these environmental stimuli are a class of integral membrane protein called Transient Receptor Potential (TRP) channels. TRP channels are a class of cationic channels that act as signal transducer by altering membrane potential or intracellular calcium $\left(\mathrm{Ca}^{2+}\right)$ concentration. The TRP channel era began in 1969 when Cosens and Manning discovered a phenotype in drosophila that exhibited as blindness in the presence of constant bright light (Cosens and Manning 1969). This mutant strain was named trp, transient receptor potential, and cloning of the mutated trp gene identified the first member of the TRP superfamily (Cosens and Manning 1969). This superfamily constitutes a diverse group of polymodal ion channels that are mostly conserved from nematodes to humans. Based on sequence homology the mammalian TRP channel superfamily is classified into six subfamilies (Fig. 6.1): TRPC (Canonical), TRPV (Vanilloid), TRPM (Melastatin), TRPA (Ankyrin), TRPML (Mucolipin), and TRPP (Polycystic). The first four subfamilies are categorized as group 1 and the last two constitute group 2 . In this chapter, each subfamily will be discussed in detail with emphasis on channels that have been extensively studied.

\subsection{TRPC Subfamily}

The first subfamily of mammalian TRP channels studied is known as the TRPC subfamily or the canonical TRP channels. The founding member TRPC1 was cloned in 1995 and was discovered based on its sequence homology to the Drosophila trp gene (Wes et al. 1995). The seven members of this subfamily are commonly divided into four groups based on sequence homology (I) TRPC1; (II) TRPC2; (III) TRPC3, TRPC6, TRPC7; and (IV) TRPC4 and TRPC5 (Fig. 6.1). Here, TRPC2, TRPC3, TRPC6 and TRPC7 will be discussed together as explained in Sect. 6.2.3.

All seven members of this subfamily are structurally similar having six transmembrane helices, a putative hydrophobic pore forming loop, three to four ankyrin repeats, coiled-coil domains in the $\mathrm{N}$ - and C-terminus, a C-terminal proline rich region, a Calmodulin/IP 3 binding region and what is known as the TRP motif (Putney 2004; Vazquez et al. 2004). TRPC channels have been shown to form both heterotetramers and homotetramers within the TRP channel superfamily, with different members having certain preferences, for example, TRPC1 forms physiologically relevant functional channels with several TRPC channels including TRPC4, as well as, TRPV1, and TRPP2 (Ong et al. 2016; Dietrich et al. 2014).

The TRPC subfamily channels, like most other TRP channels, function as $\mathrm{Ca}^{2+}$ permeable plasma membrane channels with varying $\mathrm{Ca}^{2+}$ selectivity (Vazquez et al. 2004). The mechanism of regulation of these channels is contentious, with the two main hypotheses being store-operated channel activation and receptor-activated channel regulation (Vazquez et al. 2004). It appears, based on the current body of scientific research, that different members of this subfamily are activated based on one or both of these two methods depending on the expression system, expression level and the antibody used. Other research 
has also suggested mechanosensitive gating mechanisms (Dietrich et al. 2014). In spite of these experimental limitations, much is known about this subfamily of TRP channels.

\subsubsection{TRPC1}

The founding member of this subfamily can also be considered the founding member of the mammalian TRP channel superfamily. TRPC1 was first cloned by the Montell group in 1995 because of its high sequence homology ( 40\%) to the Drosophila trp gene (Wes et al. 1995). This invertebrate $\operatorname{trp}$ gene was proposed to be a store-operated $\mathrm{Ca}^{2+}$ channel and therefore mammalian homologues had potentially the same function. TRPC1 was originally found in fetal brain, liver and kidney tissues as well as adult heart, testes, ovaries and brain (Wes et al. 1995). Since then, it has been found to be broadly expressed in mammalian tissues (Dietrich et al. 2014). TRPC1 knockout mice have emerged as a highly successful tool for research of this channel in vivo (Dietrich et al. 2014). These models have implicated TRPC1 in skeletal muscle differentiation, organism growth and development, immune regulation, tumor cell migration and Parkinson disease (Dietrich et al. 2014). In spite of being involved in these critical biological functions, TRPC1-/- mice have been reported to live a healthy and normal life (Dietrich et al. 2014).

TRPC1 monomers have been shown to create functional channels with not only other TRPC members, but also with TRP members outside its subfamily. For example, Tsiokas et al. showed that TRPC1/TRPP2 heterotetrameric channels form and operate in membrane bilayers (Dietrich et al. 2014; Tsiokas et al. 1999). TRPC1 has also been shown to interact with members of the TRPV subfamily (Dietrich et al. 2014). TRPC1 undergoes alternative splicing and there are currently five known splice variants with only three that have been shown to be translated to functional proteins (Dietrich et al. 2014). Different splice variants have been reported to affect channel functionality especially in heteromeric channels (Dietrich et al. 2014). Recently, there has also been a start codon found upstream of the currently used start codon for TRPC1. This has produced an extended form of TRPC1, which could be of interest for future studies of the protein (Dietrich et al. 2014).

As mentioned previously, TRPC1 was originally discovered as a potential store-operated $\mathrm{Ca}^{2+}$ channel, but characterization of this channel did not show it to have the predicted traits of a store operated $\mathrm{Ca}^{2+}$ channel or $I_{C R A C}$ activity (Ong et al. 2016). Still, TRPC1 has been shown to be involved in store-operated $\mathrm{Ca}^{2+}$ entry (SOCE) through its interactions with Orai1 and STIM1 thus designating it as having $I_{S O C}$ activity (Ong et al. 2016). SOCE is a signaling cascade that is critical for an abundance of biological processes. When $\mathrm{Ca}^{2+}$ is released from the endoplasmic reticulum the cytosolic $\mathrm{Ca}^{2+}$ concentration increases which triggers activation of plasma membrane $\mathrm{Ca}^{2+}$ channels $\left(I_{C R A C}\right.$ or $I_{S O C}$ ). Evidence suggests that TRPC1 colocalizes with STIM1 and Orai1 in endoplasmic reticulum-plasma membrane (EM-PM) junctions wherein these two membranes exist in close proximity to one another (Ong et al. 2016). Orai1 has been shown to be necessary for TRPC1 activation, though different splice variants of TRPC1 seem to be modulated by Orai1 differently (Ong et al. 2016). Mechanosensitivity has also been discussed as a potential regulation method for this channel, but various expression systems have provided conflicting results to date (Dietrich et al. 2014). 


\subsubsection{TRPC4 \& TRPC5}

TRPC4 and TRPC5 are often grouped with TRPC1 because they, like TRPC1, are inwardly rectifying and were originally hypothesized to be involved in SOCE (Vazquez et al. 2004). What distinguishes these two channels is their extended C-terminus that contains a PDZ binding domain. This domain has been shown to interact with NHERF, a scaffold protein that links plasma membrane proteins to the actin cytoskeleton (Voltz et al. 2001; Vazquez et al. 2004). Through this PDZ domain, TRPC4 has been shown to be activated downstream of $\mathrm{G}_{\mathrm{q}}$-coupled receptors and receptor tyrosine kinases (Clapham et al. 2005). The function of the PDZ domain in TRPC5 has not been as thoroughly explored. TRPC5 has generally been found to behave as a receptor-operated calcium channel (Vazquez et al. 2004). Both TRPC4 and TRPC5 channel currents are potentiated by lanthanides in contrast to the inhibitory effects seen in store-operated channels and other TRPC channels (Vazquez et al. 2004).

\subsubsection{TRPC2, TRPC3, TRPC6 \& TRPC7}

TRPC2 is a pseudogene and therefore is not translated in humans, but it is expressed as a functional protein in other mammals. Here, it is grouped with TRPC3, TRPC6 and TRPC7 because these four members can all be directly activated by lipids, specifically diacylglycerol (DAG), a product of phosphatidylinositol 4,5-bisphosphate $\left(\mathrm{PI}(4,5) \mathrm{P}_{2}\right)$ degradation (Svobodova and Groschner 2016). Though the other TRPC family members have been shown to be regulated by lipids, seen through their localization to lipid rafts (LRDs) and other lipid targeted cellular locations, for these four members lipid binding is necessary and sufficient for channel activation (Svobodova and Groschner 2016; Ong et al. 2016). A range of affinities for lipids has been reported for all TRPC subfamily channels, as well as a multitude of interaction mechanisms. Currently, both direct binding of lipids to cause activation, and indirect binding of lipids using adaptor proteins are possible for activation and/or localization for TRPC2, TRPC3, TRPC6 and TRPC7, since an exact lipid binding pocket has yet to be elucidated (Svobodova and Groschner 2016).

\subsection{TRPV Subfamily}

Transient receptor potential vanilloid (TRPV) channels were named based on the activation of the founding member of this group by capsaicin, a vanilloid-like molecule. This original TRPV channel was initially known as VR1 (Caterina et al. 1997). In this 1997 study, it was shown that VR1, expressed in sensory neurons, is activated by capsaicin, the active ingredient in chilies, by temperature higher than $42{ }^{\circ} \mathrm{C}$ and by protons. Due to the structural similarity of VR1 with other known TRP channels it was later renamed TRPV1.

Subsequently five additional members of this subfamily were cloned and named TRPV2, TRPV3, TRPV4, TRPV5 and TRPV6 (Fig. 6.1) (Kanzaki et al. 1999; Smith et al. 2002; Xu et al. 2002; Strotmann et al. 2000; Liedtke et al. 2000; Caterina et al. 1999). Initially all the members of TRPV subfamily were thought to be heat sensors like TRPV1, but extensive physiological studies and knockout mice later revealed that although TRPV2-6 have more than 50\% sequence homology with TRPV1, they do not all respond to temperature stimuli. Moreover, TRPV1-4 channels have nonselective cation conducting pores while the pores of TRPV5 and TRPV6 are highly calcium selective. Recently, high resolution structures of TRPV1 (Gao et al. 2016; Cao et al. 2013; Liao et al. 2013) (Fig. 6.2a, b), TRPV2 (Huynh et 
al. 2014, 2016; Zubcevic et al. 2016) (Fig. 6.2c, d) and TRPV6 (Saotome et al. 2016) (Fig. 6.2e) have been resolved using cryo-electron microscopy (cryo-EM) and X-ray crystallography which has helped to elucidate the physiological characteristics of this subfamily as a whole as well as the finer details and differences of the individual members. These structures also provide the first glimpse into the architectural details of the TRP channel superfamily.

\subsubsection{TRPV1}

TRPV1 is expressed in sensory neurons and is activated by capsaicin, protons, toxins and temperature in the noxious range $\left(>42^{\circ} \mathrm{C}\right)$, making it physiologically important for thermal and chemical nociception. To date, TRPV1 is the most well characterized and extensively studied mammalian TRP channel. These studies have provided a wealth of information about its physiological and biophysical properties as well as its role in disease and its potential as a therapeutic target.

Functional TRPV1 is a homotetramer, with each monomer consisting of six ankyrin repeats in the cytosolic N-terminal domain, a transmembrane domain containing six transmembrane helices (S1-S6) with a pore forming P-loop between S5 and S6 and a TRP domain in the cytosolic C-terminal domain. The crystal structure of the ankyrin repeat domain was solved in 2007 by Rachelle Gaudet's group (Lishko et al. 2007) and the first full length single particle cryo-EM structure of TRPV1 was resolved to $19 \AA$ $⿱$ resolution (Moiseenkova-Bell et al. 2008).

The detailed architecture of a TRP channel was first elucidated in 2013 when the structure of a truncated, functional TRPV1 channel, called "minimal TRPV1", was resolved to $3.4 \AA$ resolution (Liao et al. 2013) (Fig. 6.2a). This was also the first time that cryo-EM was used to reconstruct the 3D structure of a small membrane protein to near atomic resolution. Additionally, the structure of TRPV1 in the presence of the vanilloid agonist capsaicin and resiniferatoxin/Double-knot toxin (RTX/DkTx) were also resolved by the same group at that time to resolutions $4.2 \AA$ and $3.8 \AA$ respectively (Cao et al. 2013). This advancement in structural analysis of small proteins was possible due to the development of direct electron detectors, improved image processing algorithms that allowed correction of motion induced blurring, and the improvement of signal to noise ratio in cryo-EM data.

The near atomic resolution structure of minimal TRPV1 in the apo state displayed a fourfold symmetry along a central ion permeating pathway. The ion conducting pore is formed by transmembrane segments 5 and 6 (S5 and S6) and the pore forming P loop, which has an overall similarity to that of voltage gated $\mathrm{Na}^{+}$and $\mathrm{K}^{+}$channels. However, unlike the voltage gated ion channels where $\mathrm{S} 1-\mathrm{S} 6$ constitutes the voltage sensing domain and undergoes significant conformational rearrangement during channel gating, the S1-S4 of TRPV1 remains fairly static between closed, partially open and fully open state. Although the overall topology of the pore region is analogous to $\mathrm{Na}_{V}$ channels, TRPV1 has a flexible selectivity filter due to the absence of hydrogen bonding within and between adjacent pore helices (Liao et al. 2013). 
The flow of ions through the pore is controlled by a dual gating mechanism consisting of an upper gate located in the selectivity filter region and a lower gate formed by residue Ile679 (Fig. 6.3). Comparison of the apo state structure with the capsaicin bound and RTX/DkTx bound structures further illustrate the dual gate architecture. In the apo state, the pore is constricted both at the selectivity filter region and at the lower gate (I679). In the capsaicin bound state, capsaicin does not affect the selectivity filter region, but the lower gate expands significantly. In the RTX/DkTx bound structure there is no apparent constriction in the ionconducting path (Cao et al. 2013). Recently, the structure of TRPV1 reconstituted in nanodiscs was resolved at a higher resolution by the same group (Gao et al. 2016). The nanodisc-stabilized structures elucidated some of the important putative regions of lipid interaction with TRPV1 in a membrane bilayer system. The fully open RTX/DkTx bound state showed formation of a lipid, channel and toxin tripartite complex, suggesting how toxin binding stabilizes the open state. Aromatic side chain residues, tryptophan and phenylalnine, from finger 1 and finger 2 of the double-knot toxin forms hydrophobic interaction with the aliphatic tail of a phospholipid whose polar head group interacts with channel residues Arg534, present in the extracellular loop connecting S3 and S4, and Ser629, present in the pore loop domain, respectively. Additionally, the study also suggests the vanilloid-binding pocket, between S3, S4, S4-S5 linker and the TRP domain, to be a plausible phosphatidylinositide-binding region in the apo channel (Gao et al. 2016).

\subsubsection{TRPV2}

The second member of the TRPV subfamily, TRPV2, was cloned because of its homology to TRPV1 (Kanzaki et al. 1999; Caterina et al. 1999). Like TRPV1, TRPV2 was described as a heat sensor, specifically as a noxious heat sensor $\left(>52^{\circ} \mathrm{C}\right)$ in heterologous expression systems. However, later studies and knockout mice models suggested otherwise since TRPV2 knockout mice displayed normal thermo sensation and had prenatal lethality (Park et al. 2011).

TRPV2 is ubiquitously expressed in various tissues types including both neuronal and nonneuronal tissues. This channel has been implicated in various physiological processes, such as nerve growth, and a variety of disease states, including cancer. The Moiseenkova-Bell lab has recently shown that TRPV2 has a punctate distribution in DRG neurons and other neuronal cell lines and it co-localizes with Rab7, a late endosomal marker in these cell lines (Cohen et al. 2015). Although TRPV1 and TRPV2 have 50\% sequence homology and the overall structures at low resolution looks very similar, the near atomic resolution structures show some differences.

The structure of full length TRPV2 was first resolved at $\sim 13 \AA$ resolution in 2014 and was later resolved to $\sim 5 \AA$ in 2016 (Fig. 6.2c) (Huynh et al. 2014, 2016). This was the first time a full length TRP channel was resolved to near atomic resolution. Another group published $\sim 4$ $\AA$ resolution structure of a truncated TRPV2 construct (Fig. 6.2d) recently (Zubcevic et al. 2016). The pore region of TRPV2, like that of TRPV1, demonstrated two regions of constriction (Fig. 6.3), one in the selectivity filter region and another at the distal part S6 helix. However, the pore of full length apo TRPV2 was shown to be much wider than the pore of apo TRPV1, suggesting apo TRPV2 may be able to accommodate partially hydrated 
cations and other large organic ions. Interestingly, the lower gate of apo TRPV2 is wider than that of RTX/DkTx bound TRPV1. The truncated structure of TRPV2 in the apo state, however, had a pore similar to that of apo TRPV1, with both the gates closed. This difference in the structures of TRPV2 can be attributed to either the truncation of the pore turret region or to the differences in channel properties between different mammalian orthologous (mouse vs rabbit).

\subsubsection{TRPV3 \& TRPV4}

TRPV3 and TRPV4 were also cloned and hypothesized to be heat sensors due to their homology to TRPV1. TRPV3 was found to be responsible for detecting innocuous warm temperature ranging from 31 to $39^{\circ} \mathrm{C}$. It is expressed in various tissues and organs, but the most pronounced expression of TRPV3 is in the epithelial cells of skin, the oral cavity and the gastrointestinal tract. TRPV3 knockout mice had strong deficit in response to innocuous heat sensitivity (Moqrich et al. 2005). However, a later study demonstrated that this deficit in thermo sensation was dependent on the background strain used for developing the knockout mice (Huang et al. 2011). Recently, TRPV3 has gained importance as a channel essential in maintaining skin health.

The role of TRPV4 in thermo sensation is also controversial with studies done in heterologous expression systems, native tissues and knockout mice giving conflicting results (Garcia-Elias et al. 2014; Guler et al. 2002; Huang et al. 2011). TRPV4 has a wide and varied expression pattern in the body (Everaerts et al. 2010). It has been shown to respond to osmotic changes in cellular environment and mechanical stress (Liedtke and Friedman 2003; Strotmann et al. 2000; Wu et al. 2007; Gao et al. 2003; Kohler et al. 2006). Therefore, it has an established role in osmoregulation and mechanotransduction in the body.

\subsubsection{TRPV5 \& TRPV6}

TRPV5 and TRPV6 are unique from other TRP channels in that they are highly calcium selective. Therefore, they have a significant contribution in calcium homeostasis in the body. TRPV5 and TRPV6 have high sequence homology $(\sim 75 \%)$ at the amino acid level and can form both homotetrameric and heterotetrameric functional units (Hoenderop et al. 2003). TRPV5 is exclusively expressed in the kidney, while TRPV6 has a wide tissue distribution, including in intestinal, pancreatic and placental tissues. Both TRPV5 and TRPV6 are present in the apical membrane of the epithelial cells and act as the entryway for $\mathrm{Ca}^{2+}$ during absorption and reabsorption. They are constitutively active channels when present in the plasma membrane, but are inactivated in the presence of high $\mathrm{Ca}^{2+}$, preventing $\mathrm{Ca}^{2+}$ poisoning of the cells.

Recently the crystal structure of TRPV6 was resolved with some modifications (TRPV6 $6_{\text {cryst }}$ ) at $3.2 \AA$ (Saotome et al. 2016) (Fig. 6.2e). Overall the structure is very similar to that of TRPV1 and TRPV2 (Cao et al. 2013; Huynh et al. 2016). The ion conducting pathway has two gates, one in the selectivity filter region formed by Asp541, which is critical for calcium selectivity, and the other at the lower end of the pore formed by Met577, similar to that of full length TRPV2 structure (Huynh et al. 2016). It was proposed that the selectivity filter of TRPV6 is more static in contrast to other TRPV channels. The flexibility of the selectivity 
filter was thought to be required for pore dilation as seen in ligand bound TRPV1 channel structures(Cao et al. 2013). A highly electro-negative outer region of the pore likely assists in the recruitment of $\mathrm{Ca}^{2+}$ ions to the pore. It was further proposed that calcium permeation of TRPV6 occurs via a "knock-off" mechanism similar to that of $\mathrm{Ca}_{\mathrm{v}}$ channels and the ratelimiting step in this process is knocking off the $\mathrm{Ca}^{2+}$ ion from D541 site (Saotome et al. 2016).

\subsection{TRPM Subfamily}

The melastatin-related TRP (TRPM) subfamily contains similar structural regions compared to the other TRP subfamilies, including the presence of six membrane spanning regions, cytoplasmic C- and N-terminal domains and a C-terminal TRP motif (Kraft and Harteneck 2005). TRPM channels also contain a C-terminal tetrameric coiled-coil domain, the structure of which was solved by the Minor Jr. group in 2008 using X-ray crystallography (Fujiwara and Minor 2008). Interestingly, each member of this subfamily contains an N-terminal 'TRPM homology region' that is involved in channel assembly and trafficking that is not seen in other TRP channels (Kraft and Harteneck 2005). Another defining characteristic of this subfamily is the lack of N-terminal ankyrin repeats that is commonly seen in other subfamilies (Kraft and Harteneck 2005). The large C-terminal sections of TRPM channels are highly varied between subfamily members with TRPM2, TRPM6 and TRPM7 containing active enzymatic domains in this region.

Originally, most members of this subfamily were cloned from cancerous tissues and were therefore implicated in tumorigenesis, proliferation and differentiation (Kraft and Harteneck 2005). After nearly two decades of research, members of this subfamily have also been found to be involved in temperature sensation, magnesium $\left(\mathrm{Mg}^{2+}\right)$ homeostasis and taste (Fujiwara and Minor 2008; Hashimoto and Kambe 2015). The TRPM subfamily has been shown to have vastly differing modes of activation, cation selectivities and tissue distributions (Hofmann et al. 2003). Here, the TRPM subfamily is presented in four groups based on structural similarity (I) TRPM1 \& TRPM3 (II) TRPM4 \& TRPM5 (III) TRPM2, TRPM6 \& TRPM7 and (IV) TRPM8 (Fig. 6.1).

\subsubsection{TRPM1 \& TRPM3}

The first member of the TRPM subfamily, TRPM1, originally named melastatin, is a $\mathrm{Ca}^{2+}$ permeable ion channel that was first cloned from benign melanomas (Duncan et al. 1998). This protein was found to be an indicator of melanoma aggressiveness since it was found to be expressed at higher levels in non-metastatic melanomas (Duncan et al. 1998). Due to this correlation, TRPM1 was found to be a tumor suppressor and a potential prognostic marker for metastatic melanomas (Brozyna et al. 2016). In non-cancerous human tissues, TRPM1 is found only in the brain, melanocytes, macrophages and heart, all at very low levels (Fonfria et al. 2006).

TRPM3 is a $\mathrm{Ca}^{2+}$ permeable, non-selective cation channel that can function as a homotetramer or in complex with TRPM1 (Held et al. 2015). Molecular activators of TRPM3 include sphingolipids, pregnenolone sulfate (PS), and nifedipine (Held et al. 2015). Other stimuli of TRPM3 include cell swelling and heat $\left(40^{\circ} \mathrm{C}\right)($ Held et al. 2015). Although 
TRPM3 was originally thought to be involved in glucose induced insulin release in the $\beta$ cells of the pancreas, TRPM3 knockout mice showed normal glucose metabolism (Held et al. 2015). Other studies have shown that physiologically TRPM3 plays an important role in heat sensation in the somatosensory system (Held et al. 2015). Mutations in TRPM3 have been found in hereditary eye diseases such as cataracts and some high-tension glaucomas (Held et al. 2015).

\subsubsection{TRPM4 \& TPRM5}

Both TRPM4 and TRPM5 are distinct from the other members of the TRPM subfamily, and the TRP family of channels in general, because they are impermeable to $\mathrm{Ca}^{2+}$ (Zholos et al. 2011). Rather, they are only permeable to monovalent cations including sodium $\left(\mathrm{Na}^{+}\right)$and potassium $\left(\mathrm{K}^{+}\right)$(Zholos et al. 2011). Because of this, TRPM4 and TRPM5 are considered to be $\mathrm{Ca}^{2+}$ activated, non-specific cation (CAN) channels (Kraft and Harteneck 2005). Voltage modulation of both of these channels has been reported and the sensitivity to $\mathrm{Ca}^{2+}$ gating of these channels can be altered by changes in temperature, calmodulin binding, $\mathrm{PIP}_{2}$ binding and channel phosphorylation (Zholos et al. 2011).

TRPM4 is highly expressed throughout the body with high levels present in the intestine and prostate (Fonfria et al. 2006). TRPM5, on the other hand, is expressed in discrete tissues with high expression in the intestines and taste buds (Fonfria et al. 2006; Zholos et al. 2011). In the taste buds, TRPM5 has been shown to be a transducer of bitter, sweet and umami taste sensation (Liman 2007). This was confirmed using mice models lacking functional TRPM5. These mice exhibited a drastic reduction in response to those tastes, while sour and salty taste sensations were unaffected (Liman 2007). Bitter, sweet and umami taste sensations are regulated by G-protein coupled receptor signal cascades and TRPM5 is thought to be a downstream target of these pathways (Liman 2007). The role of TRPM5 in the intestines is thought to be related to post-ingestion chemosensation (Liman 2007).

\subsubsection{TRPM2, TRPM6 \& TRPM7}

TRPM2, TRPM6 and TRPM7 are unique because they are bifunctional proteins. In addition to being cation permeable channels, these TRPM members also contain functional enzymatic domains in their C-terminal segments (Kraft and Harteneck 2005). The catalytic domain of TRPM2 has sequence homology to Nudix hydrolases. TRPM2 has been shown to be activated by ADP-ribose and reactive oxygen species (ROS), which implicates this channel in cellular redox sensation (Kraft and Harteneck 2005). TRPM2 is permeable to $\mathrm{Ca}^{2+}, \mathrm{Mg}^{2+}$, and monovalent cations (Kraft and Harteneck 2005). In human tissues, TRPM2 was found to be widely expressed with the highest levels in the brain, macrophages and bone marrow (Fonfria et al. 2006).

TRPM6 and TRPM7 are highly sequence homologous and hence both have the ability to permeate $\mathrm{Mg}^{2+}, \mathrm{Zn}^{2+}$ and $\mathrm{Ca}^{2+}$, though they are most often studied for their role in the whole organism and cellular $\mathrm{Mg}^{2+}$ homeostasis (Komiya and Runnels 2015). The enzymatic domains of these two channels are classified as atypical alpha protein kinases (Kraft and Harteneck 2005). These two TRPM members have been shown to form functional heterotetrameric channels ( $\mathrm{Li}$ et al. 2006). A lack of either TRPM6 or TRPM7 was found to 
be embryonically lethal and several magnesium-related diseases have been linked to mutations in these channels. For example, autosomal-recessive hypomagnesemia with secondary hypocalcemia (HSH) is correlated to mutations in the TRPM6 gene (Nilius et al. 2007).

In spite of these similarities, the tissue distributions of TRPM6 and TRPM7 are widely divergent. TRPM6 is found at highest levels in the intestines where it has been shown to be involved in dietary $\mathrm{Mg}^{2+}$ uptake (Hashimoto and Kambe 2015; Fonfria et al. 2006). It is also found at relatively high levels in the brain, pituitary, and the distal convoluted tubule (DCT) of the kidney (Fonfria et al. 2006). TRPM7, on the other hand, is ubiquitously expressed in the human body (Fonfria et al. 2006).

\subsubsection{TRPM8}

One of the most thoroughly explored members of this subfamily is TRPM8, which is best known for its cold sensing ability. In addition to thermosensation, TRPM8 has also been shown to be involved in pain sensation, thermoregulation, bladder function and cancer (Liu et al. 2016). TRPM8 is a non-selective, $\mathrm{Ca}^{2+}$ permeable, outwardly rectifying cation channel (McKemy 2007; Liu et al. 2016). Of the TRPM subfamily, TRPM8 is the most selective for $\mathrm{Ca}^{2+}$ with a selectivity ratio $\left(\mathrm{P}_{\mathrm{Ca}} / \mathrm{P}_{\mathrm{Na}}\right)$ of 3.3 (Zholos et al. 2011). This channel was originally cloned from a prostate cDNA library screen (Tsavaler et al. 2001). It was found to be involved in prostate cancer, specifically there was found to be an androgen dependent overexpression of TRPM8 in androgen receptor positive prostate cancers (Liu et al. 2016). TRPM8 is involved in a variety of other cancers including adenocarcinoma, melanomas, as well as lung and breast cancers (Liu et al. 2016). In 2002, two independent research groups identified TRPM8 as a cold $\left(<28^{\circ} \mathrm{C}\right)$ and menthol activated ion channel (McKemy et al. 2002; Peier et al. 2002). Other chemical agonists for TRPM8 include cooling agents such as eucalyptol and icilin (Liu et al. 2016). The temperature threshold of TRPM8 can be modulated by changes in membrane potential, arachidonic acid, lysophospholipids and $\mathrm{PIP}_{2}$ (Liu et al. 2016). There is also evidence that G-proteins are involved in regulation of TRPM8, specifically, Gaq is involved in the inflammation mediated inhibition of TRPM8 (Liu et al. 2016).

\subsection{TRPA Subfamily}

Transient receptor potential ankyrin 1 (TRPA1) is the solitary member of the mammalian TRPA subfamily (Fig. 6.1). It was discovered as an ankyrin-like transmembrane protein, with similarities to existing TRP channels (Jaquemar et al. 1999). Like other TRP channels, TRPA1 also has a cytosolic $\mathrm{N}$-terminal domain, a transmembrane domain containing six transmembrane helices with a transmembrane loop between S5 and S6 and a cytosolic Cterminal domain. It is a unique channel within the superfamily in that it lacks the TRP motif and it contains 14-17 ankyrin repeats in the N-terminal domain. This abundance of ankyrin repeats is why it is known as the ankyrin subfamily. TRPA1 was proposed to be a putative noxious cold sensor, but it is now best described as chemo-nociceptor, making it an ideal target for analgesics (Story et al. 2003). The TRPA1 channel is expressed in both peptidergic and non-peptidergic neurons like $\mathrm{A} \delta$ and $\mathrm{C}$-fiber and in some myelinated $\mathrm{A} \beta$-fibers 
(Zygmunt and Hogestatt 2014). It is also expressed in TRPV1 expressing neurons and in non-neuronal cells such as epithelial cells, melanocytes, mast cells, fibroblasts, and enterochromaffin cells (Zygmunt and Hogestatt 2014).

TRPA1 is a polymodal channel in a true sense. It is a homotetrameric, non-selective cation channel, activated by a long list of exogenous and endogenous compounds. The most wellknown activators of TRPA1 are various cysteine and lysine reactive electrophilic molecules like allyl isothiocyanate (AITC), the active ingredient in mustard oil and wasabi, cinnamaldehyde which is an extract from cinnamon, allicin from garlic extract and acrolein from fume exhaust (Bautista et al. 2006; Bandell et al. 2004; Nilius et al. 2012). Additionally, TRPA1 is also activated by non-electrophilic molecules like menthol and cannabinoids (Jordt et al. 2004; Karashima et al. 2007). It is also modulated by various endogenous ligands like bradykinin, $\mathrm{H}_{2} \mathrm{O}_{2}$, and nitrated lipids like nitro oleic acid (Bandell et al. 2004; Takahashi et al. 2011; Takahashi and Mori 2011). Mutational studies along with other biochemical, electrophysiological and biophysical methods have established that the reactive ligands interact with TRPA1 via a cluster of cysteine and lysine residues present in the N-terminus of the channel (Hinman et al. 2006; Macpherson et al. 2007), but the molecular mechanism of TRPA1 channel modulation by non-reactive ligands is still largely unknown.

The first glimpse into the structure of TRPA1 was provided by a $\sim 16 \AA$ resolution EM structure resolved by the Moiseenkova-Bell lab in 2011 (Cvetkov et al. 2011). Although this structure provided insight regarding the boundaries of the transmembrane domain and cytoplasmic domain, it gave no information about the molecular architecture of TRPA1. In 2015, a near atomic resolution structure of TRPA 1 at $\sim 4 \AA$ was resolved using cryo-EM (Fig. 6.2f) (Paulsen et al. 2015). Although full length protein was used for cryo-EM, 3D reconstruction was only successful for $\sim 50 \%$ of the channel. Overall, the transmembrane domain structure resembles those of TRPV1 and V2 structures, containing six transmembrane helices and a reentrant pore loop, with some differences in the pore region. The ion path is gated by two restriction points, the upper gate is formed by Asp915 (Gly643 and Met644 in TRPV1) and the lower gate is made up of two hydrophobic residues Ile957 and Val961 (Ile679 in TRPV1) (Fig. 6.3). The outer region of the pore has two short pore helices similar to those seen in $\mathrm{Na}_{\mathrm{v}}$ channels. In the cytoplasmic region, the C-terminus forms a coiled coil central stalk-like domain, which is flanked by the ankyrin repeats of the $\mathrm{N}$-terminus. Human TRPA1 is thought to have at least 16 ankyrin repeats, out of which only five were resolved in this $\sim 4 \AA$ structure, with the other 11 ankyrin repeats remaining unresolved (Fig. 6.2f) (Paulsen et al. 2015). 3D reconstructions of TRPA1 both in the presence of agonist and antagonists were performed, but no differences between the open and closed structures were identified. Therefore, these structures have served to elucidate the general molecular structure of TRPA1, but a full length TRPA1 structure and the molecular mechanisms of channel activation have remained elusive.

\subsection{TRPML Subfamily}

The mucolipin transient receptor potential (TRPML) subfamily consists of three $\mathrm{Ca}^{2+}$ permeable cation channels known as TRPML1 (MCOLN1), TRPML2 (MCOLN2) and 
TRPML3 (MCOLN3) (Fig. 6.1). Physically, these channels are the smallest in the TRP superfamily with each channel measuring $<600$ amino acids in length (Noben-Trauth 2011; Flores and García-Añoveros 2011; Colletti and Kiselyov 2011). Though they have the typical TRP six transmembrane segments with cytosolic $\mathrm{N}$ - and C-termini, this subfamily has not been reported to contain any ankyrin repeats or a complete TRP motif (NobenTrauth 2011; Flores and García-Añoveros 2011; Colletti and Kiselyov 2011). Additionally, these channels unlike others in the family are mostly localized to intracellular compartments instead of the plasma membrane (Venkatachalam et al. 2015). The localization of these channels is controlled by two di-leucine motifs, one in the N-terminus and the other in the C-terminus (Wang et al. 2014). Their function in intracellular compartments is not completely understood, but they are implicated in a variety of vesicular trafficking events (Venkatachalam et al. 2015). Another distinguishing feature of this subfamily is the presence of a large highly N-glycosylated luminal loop between the first and second transmembrane segments (Wang et al. 2014). Homomeric and heteromeric complexes for all three channels have been reported (Cuajungco et al. 2016).

\subsubsection{TRPML1}

The first member of the TRPML subfamily was discovered because of its role in the autosomal-recessive lysosomal storage disease (LSD) known as type IV mucolipidosis (MLIV) (Bassi et al. 2000). Patients with ML-IV have a mutation in the TRPML1 gene which manifests on a cellular level as an accumulation of late endosomes and lysosomes (LELs) and a build up of lysosomal storage materials (Wang et al. 2014). These patients show cognitive impairment and compromised motor skills beginning in years 1-2 of life and this disorder has been shown to have a degenerative component (Venkatachalam et al. 2015). Research regarding TRPML1 tends to focus on understanding this disease in order to produce treatments for these patients.

TRPML1 is an inwardly rectifying $\mathrm{Ca}^{2+}$ permeable cation channel that is localized to LELs (Wang et al. 2014). This channel is ubiquitously expressed and has been shown to be involved in membrane trafficking, signal transduction, and LEL ion homeostasis (Wang et al. 2014). Currently there are no known splice variants of human TRPML1 (Wang et al. 2014). There is a predicted phosphatidylinositol 3,4-bisphosphate $\left(\mathrm{PI}(3,5) \mathrm{P}_{2}\right)$ binding site in the N-terminus of this protein and, like TRPML2 and TRPML3, the presence of PI(3,5) $\mathrm{P}_{2}$ activates the channel (Wang et al. 2014). For TRPML1, it has also been reported that phosphatidylinositol 4,5-bisphosphate $\left(\mathrm{PI}(4,5) \mathrm{P}_{2}\right)$ can inhibit activation (Venkatachalam et al. 2015). This is interesting because $\mathrm{PI}(3,5) \mathrm{P}_{2}$ is found in higher abundance in intracellular vesicles and $\mathrm{PI}(4,5) \mathrm{P}_{2}$ is present mostly on the plasma membrane (Venkatachalam et al. 2015; Wang et al. 2014). This could potentially mean that even though TRPML1 can be found on the plasma membrane, it may not be active due to the presence of $\mathrm{PI}(4,5) \mathrm{P}_{2}$ (Wang et al. 2014; Venkatachalam et al. 2015). TRPML1 is permeable to a wide range of divalent and monovalent cations including $\mathrm{Ca}^{2+}, \mathrm{Fe}^{2+}, \mathrm{Na}^{+}$and $\mathrm{K}^{+}$. While TRPML1 is not permeable to protons, it is $\mathrm{pH}$ sensitive (Wang et al. 2014). 


\subsubsection{TRPML2 \& TRPML3}

TRPML2 is the least studied of this subfamily because it has not been implicated in any disease or phenotype (Cuajungco et al. 2016). Trafficking of TRPML2 is mediated via the ADP-ribosylation factor (ARF)-6 associated pathway (Venkatachalam et al. 2015). This channel is found primarily in lymphoid and myeloid tissues and due to this distribution, recent studies have focused on the role of TRPML2 in the immune system (Cuajungco et al. 2016). TRPML2 co-localizes with several immune-associated proteins such as MHC-I, TLRs and Fc-eRI and is thought to be involved in trafficking these proteins (Cuajungco et al. 2016). Unlike many other TRP channels TRPML2 is not regulated by changes in $\mathrm{Ca}^{2+}$ levels or linoleic acid, but it is, as mentioned previously, activated by the presence of $\mathrm{PI}(3,5) \mathrm{P}_{2}$ and is $\mathrm{pH}$ sensitive (Cuajungco et al. 2016; Wang et al. 2014).

While TRPML3, like TRPML2, does not have any known role in human diseases, this channel is of interest because of its involvement in varitint-waddler ( Va) mouse phenotypes (Cuajungco et al. 2016). In short, the gain of function mutation A419P in TRPML3 causes a $\mathrm{Ca}^{2+}$ overload in melanocytes which results in a hearing loss, vestibular disfunction and abnormal pigmentation in mice (Cuajungco et al. 2016). Additionally, a correlation has been shown between down-regulated TRPML3 and viral and bacterial infections such as cytomegalovirus infection, hemophilus infection and chlamydial infection (Grimm et al. 2014).

TRPML3 is localized to early endosomes, recycling endosomes, and LELs (Grimm et al. 2014). The tissue distribution of TRPML 3 is broad with higher expression levels in the organs of the endocrine system as well as the kidney, intestines and lungs (Grimm et al. 2014). High sodium levels and low pH have been shown to inactivate this channel (Grimm et al. 2014). The $\mathrm{pH}$ sensitivity of this channel is controlled by regions in the luminal loop between first and second transmembrane region (Grimm et al. 2014). Several splice variants of human TRPML3 have been reported (Grimm et al. 2014). TRPML3 knockout mice have been shown to live healthy normal lives, though the model is limited due to the differences in tissue expression of TRPML3 in mice and humans (Grimm et al. 2014).

\subsection{TRPP Subfamily}

The transient receptor potential polycystin subfamily of TRP channels consists of integral membrane proteins, mutations in which attribute to the pathological condition called autosomal dominant polycystic kidney disease (ADPKD). The founding members of this group, TRPP2 (PKD2) and TRPP1 (PKD1) were identified by positional cloning of disease causing genes of ADPKD (Mochizuki et al. 1996; Consortium 1994; Hughes et al. 1995).

ADPKD is one of the most common, monogenic, progressive disorders affecting 1 in 4001000 humans. It is characterized by formation of fluid filled cysts and enlargement of the kidneys gradually leading to renal failure. ADPKD is also associated with formation of cysts in extra-renal tissues like the liver, kidney stone formation, as well as hypertension and cardiovascular abnormalities. Mutation of the PKD1 gene accounts for $85 \%$ of the disease and the PKD2 gene mutation account for all other cases. These two mutations have indistinguishable pathologies. 
The TRPP subfamily of TRP channel is present throughout the animal kingdom and yeast, making it likely the most ancient member of the TRP family (Venkatachalam and Montell 2007). TRPP2 is structurally homologous to other TRP channels in having six transmembrane helices and intracellular amino and carboxyl termini. However, TRPP1 has a large extracellular $\mathrm{N}$-terminus, 11 transmembrane helices and a relatively small cytoplasmic C-terminus. It does not have much semblance to the prototypical TRP channel structure and is also not a functional ion channel. Therefore, it was renamed as Polycystin1 (PC1), an integral membrane glycoprotein. Polycystin1 together with TRPP2 form a receptor-channel signaling complex, which plays important physiological roles from maintaining left-right symmetry to tubular morphogenesis. After the discovery of the two founding members, two other TRPP proteins, TRPP3 and TRPP5 (Fig. 6.1) and four other Polycystin1-like proteins, PKD1L1, PKD1L2, PKD1L3 and PKDREJ (TRPP4) were identified.

\subsubsection{Polycystin Family}

Polycystin1 (PC1), one of the founding members of the TRPP subfamily, is a $462 \mathrm{kDa}$ integral membrane protein whose domain architecture suggests that it is involved in receptor signaling and cell adhesion. Polycystin1 has a wide tissue distribution and is highly expressed in the tubular epithelial cells of the kidney, pancreas, liver and brain. Perinatal lethality of knockout mice due to large cystic kidneys suggests that Polycystin1 plays an important developmental role in the kidney (Lu et al. 1997). In the fetal kidney, Polycistin1 is present in both the apical and basolateral side of the tubular epithelial cells. However, in the adult kidney it is localized to the basolateral side at the interface between cell contact and extracellular matrix (Wilson 2001). Polycystin1 forms multiprotein complexes with various cell adhesion proteins thereby participating in cell adhesion. It also forms a signaling complex with TRPP2 where Polcystin1 may act as a receptor for the TRPP2 ion channel. Although, Polycystin1 was initially named as TRPP1, due to its lack of significant structural and functional characteristics of a TRP channel, its nomenclature has been changed to Polycystin1.

To-date, no structure of Polycystin1 is available, but from sequence analysis it is predicted to have a large extracellular $\mathrm{N}$-terminus with various motifs for protein-protein and proteinligand interaction, a transmembrane domain containing 11 transmembrane helices and a relatively small C-terminus. The extracellular domain contains two cysteine flanked, leucine rich domains that have been shown to interact with various extracellular matrix proteins like collagen type 1, laminin and fibronectin (Malhas et al. 2002). It also has a putative C-type lectin domain similar to those found in selectin and might play role in protein carbohydrate interaction and $\mathrm{Ca}^{2+}$ sensitivity. The most interesting feature of the large extracellular domain of Polycystin1 is the presence of 16 immunoglobulin (IG) like PKD domains (Fig. 6.4). The 10th PKD domain is highly conserved between humans and Fugu fish suggesting a role in ligand binding. The most distal part of the extracellular domain contains a stretch of 1000 amino acid residues that is homologous to the sea urchin for egg jelly (REJ). The REJ domain is required for proteolytic cleavage of the extracellular domain of Polycistin1 in a Gprotein coupled receptor proteolytic site (Qian et al. 2002). The transmembrane domain of Polycystin1 has 11 transmembrane helices (S1-S11) out of which S6-S11 share high sequence homology to the transmembrane domain of TRPP2 protein and contains an 
equivalent loop domain between S6 and S7. The short C-terminus of Polycystin1 has multiple potential phosphorylation sites and is involved in protein-protein interaction. It has a putative coiled coil domain that interacts with TRPP2, forming the receptor-channel complex (Fig. 6.4). The C-terminus can be cleaved and translocated to the nucleus in a process resembling Notch-mediated signaling via regulated intramembrane proteolysis (Chauvet et al. 2004).

Four other proteins that are related to Polycystin 1 were identified by homology cloning and are now part of the Polycystin family. The members of Polycystin family have high sequence homology in their transmembrane segment but lower sequence similarity in the C-terminus and $\mathrm{N}$-terminus. However, the family can be further categorized into two subsets based on their structural and physiological characteristics. PC1 and PKD1L1, both have a coiled coil domain in their C-terminus, but lack a functional ion channel-forming motif. On the contrary, PKD1L2, PKD1L3 and PKDREJ contain an ion transport motif but lack the coiled coil domain in the $\mathrm{C}$-terminus.

\subsubsection{TRPP2, TRPP3 and TRPP5}

TRPP2, a founding member of the TRPP subfamily, is the quintessential TRPP protein with an overall structural homology to other TRP ion channels. It has a ubiquitous expression pattern in the body although its precise subcellular localization and intracellular trafficking is debated, but there is general agreement about its presence in the primary cilia. TRPP2 is a tetrameric, nonselective monovalent and divalent cation permeable channel implicated in a wide array of cellular functions including fertilization, proliferation, mechanosensation and polarity (Giamarchi et al. 2006). Each monomer of TRPP2 is a $\sim 110 \mathrm{kDa}$ protein containing a cytosolic $\mathrm{N}$-terminal domain, a transmembrane domain made of six transmembrane helices (S1-S6) with a pore forming loop between S5 and S6 and a cytosolic C-terminus. The Ntermini of TRPP channels are devoid of ankyrin repeats, but the C-terminal region contains a coiled coil domain, which is likely involved in protein-protein interaction, and an EF-hand motif. A unique feature of TRPP channels is the presence of a large extracellular loop between S1 and S2 consisting of 245 amino acid residues in TRPP2, 224 residues in TRPP3 and 225 amino acid residues in TRPP5 proteins.

Recently the structure of a "minimal" TRPP2 (hPKD2:198-703) construct reconstituted in nanodiscs and "truncated PC2 construct" in detergent were resolved to $3 \AA$ and $4.2 \AA$ resolution respectively, using cryo-EM (Fig. 6.2g, h) (Shen et al. 2016; Grieben et al. 2016). This structure gives a detailed understanding of the architecture of TRPP transmembrane domain. Overall the topology of this region is similar to other known Group1 TRP protein structures (TRPV1, TRPV2 and TRPA1) with S1 - S4 forming the voltage sensing domain (VSD) and S5 and S6 along with the reentrant pore loop forming the ion-conducting pathway. The pore of the TRPP2 channel also has two points of restriction, one residing in the selectivity filter region (Ile641, Gly642 and Asp643) and the second one located at the distal end of the pore (Leu677 and Asn681) near the inner leaflet of the bilayer (Fig. 6.3). The archetypical extracellular loop between S1 and S2 of TRPP proteins is named as the "polycystin" domain by the authors and acquires a novel three-layered fold; with the top layer comprising three $a$ helices, the second layer made up of a five-stranded antiparallel $\beta$ - 
sheet and the third layer consisting of two fingers (finger 1 and finger 2). This polcystin domain contributes to channel assembly via interaction with adjacent polycystin domain of other subunits and might also be instrumental in allosterically modulating the channel due its strategic location above the VSD.

TRPP3 was the first homologue of TRPP2 to be identified (Veldhuisen et al. 1999) followed by TRPP5. TRPP3 and TRPP5 have high levels of sequence homology to the transmembrane segment of TRPP2, 78\% and 71\% respectively. However, the amino and the carboxyl termini have a very low degree of sequence homology. The major difference between TRPP2 and TRPP3 is in their amino termini where TRPP3 lacks a 100 amino acid segment. TRPP3 is expressed in a wide variety of tissues including neurons, testis, kidney and non-myocyte cardiac tissue. The precise physiological function of TRPP3 and TRPP5 is still elusive.

\subsection{Conclusions}

TRP channels are polymodal channels in a true sense, in that most of the superfamily members can be activated by a multitude of stimuli. They were known to be vital for sensory physiology, but recent studies have established that TRP channels are crucial players in various other physiological and pathological conditions like cancer, renal physiology, cardiac health and neuronal development. Therefore, most TRP channels are important therapeutic targets. Though there is much known about these channels, much controversy exists in this field regarding their physiological functions. This may be a result of the majority of the TRP channels originally being identified through sequence homology rather than function derived identification. Recent advancement in the field of cryo-EM has enabled near atomic resolution structures of some of the TRP channels, giving a glimpse into their molecular architecture. The structural information will help in establishing some of the functional characteristics of these channels and will also be beneficial for drug development. Resolving more structures will be important for the better understanding this family of ion channels.

\section{References}

Bandell M, Story GM, Hwang SW, Viswanath V, Eid SR, Petrus MJ, Earley TJ, Patapoutian A. Noxious cold ion channel TRPA1 is activated by pungent compounds and bradykinin. Neuron. 2004; 41(6):849-857. [PubMed: 15046718]

Bassi MT, Manzoni M, Monti E, Pizzo MT, Ballabio A, Borsani G. Cloning of the gene encoding a novel integral membrane protein, mucolipidin-and identification of the two major founder mutations causing mucolipidosis type IV. Am J Hum Genet. 2000; 67(5):1110-1120. DOI: 10.1016/ s0002-9297(07)62941-3 [PubMed: 11013137]

Bautista DM, Jordt SE, Nikai T, Tsuruda PR, Read AJ, Poblete J, Yamoah EN, Basbaum AI, Julius D. TRPA1 mediates the inflammatory actions of environmental irritants and proalgesic agents. Cell. 2006; 124(6):1269-1282. DOI: 10.1016/j.cell.2006.02.023 [PubMed: 16564016]

Brozyna, AA., Guo, H., Yang, SE., Cornelius, L., Linette, G., Murphy, M., Sheehan, C., Ross, J., Slominski, A., Andrew Carlson, J. TRPM1 (melastatin) expression is an independent predictor of overall survival in clinical AJCC stage I and II melanoma patients. J Cutan Pathol2016

Cao E, Liao M, Cheng Y, Julius D. TRPV1 structures in distinct conformations reveal activation mechanisms. Nature. 2013; 504(7478):113-118. DOI: 10.1038/nature12823 [PubMed: 24305161] 
Caterina MJ, Schumacher MA, Tominaga M, Rosen TA, Levine JD, Julius D. The capsaicin receptor: a heat-activated ion channel in the pain pathway. Nature. 1997; 389(6653):816-824. DOI: 10.1038/39807 [PubMed: 9349813]

Caterina MJ, Rosen TA, Tominaga M, Brake AJ, Julius D. A capsaicin-receptor homologue with a high threshold for noxious heat. Nature. 1999; 398(6726):436-441. DOI: 10.1038/18906 [PubMed: 10201375]

Chauvet V, Tian X, Husson H, Grimm DH, Wang T, Hiesberger T, Igarashi P, Bennett AM, Ibraghimov-Beskrovnaya O, Somlo S, Caplan MJ. Mechanical stimuli induce cleavage and nuclear translocation of the polycystin-1 C terminus. J Clin Invest. 2004; 114(10):1433-1443. DOI: 10.1172/jci21753 [PubMed: 15545994]

Clapham DE, Julius D, Montell C, Schultz G. International union of pharmacology. XLIX. Nomenclature and structure-function relationships of transient receptor potential channels. Pharmacol Rev. 2005; 57(4):427-450. DOI: 10.1124/pr.57.4.6 [PubMed: 16382100]

Cohen MR, Johnson WM, Pilat JM, Kiselar J, DeFrancesco-Lisowitz A, Zigmond RE, MoiseenkovaBell VY. Nerve growth factor regulates transient receptor potential vanilloid 2 via extracellular signal-regulated kinase signaling to enhance neurite outgrowth in developing neurons. Mol Cell Biol. 2015; 35(24):4238-4252. DOI: 10.1128/MCB.00549-15 [PubMed: 26416880]

Colletti, GA., Kiselyov, K. TRPML1. In: Islam, MS., editorTransient receptor potential channelsSpringer Netherlands: Dordrecht; 2011209-219

Consortium TEPKD. The polycystic kidney disease 1 gene encodes a $14 \mathrm{~kb}$ transcript and lies within a duplicated region on chromosome 16. The European Polycystic Kidney Disease Consortium. Cell. 1994; 77(6):881-894. [PubMed: 8004675]

Cosens DJ, Manning A. Abnormal electroretinogram from a Drosophila mutant. Nature. 1969; 224(5216):285-287. [PubMed: 5344615]

Cuajungco MP, Silva J, Habibi A, Valadez JA. The mucolipin-2 (TRPML2) ion channel: a tissuespecific protein crucial to normal cell function. Pflugers Arch - Eur J Physiol. 2016; 468(2):177192. DOI: $10.1007 / \mathrm{s} 00424-015-1732-2$ [PubMed: 26336837]

Cvetkov TL, Huynh KW, Cohen MR, Moiseenkova-Bell VY. Molecular architecture and subunit organization of TRPA1 ion channel revealed by electron microscopy. J Biol Chem. 2011; 286(44): 38168-38176. DOI: 10.1074/jbc.M111.288993 [PubMed: 21908607]

Dietrich A, Fahlbusch M, Gudermann T. Classical transient receptor potential 1 (TRPC1): channel or channel regulator? Cell. 2014; 3(4):939-962. DOI: 10.3390/cells3040939

Duncan LM, Deeds J, Hunter J, Shao J, Holmgren LM, Woolf EA, Tepper RI, Shyjan AW. Downregulation of the novel gene melastatin correlates with potential for melanoma metastasis. Cancer Res. 1998; 58(7):1515-1520. [PubMed: 9537257]

Everaerts W, Nilius B, Owsianik G. The vanilloid transient receptor potential channel TRPV4: from structure to disease. Prog Biophys Mol Biol. 2010; 103(1):2-17. DOI: 10.1016/j.pbiomolbio. 2009.10.002 [PubMed: 19835908]

Flores, EN., García-Añoveros, J. TRPML2 and the evolution of mucolipins. In: Islam, MS., editorTransient receptor potential channelsSpringer Netherlands: Dordrecht; 2011221-228

Fonfria E, Murdock PR, Cusdin FS, Benham CD, Kelsell RE, McNulty S. Tissue distribution profiles of the human TRPM cation channel family. J Recept Signal Transduct Res. 2006; 26(3):159-178. DOI: 10.1080/10799890600637506 [PubMed: 16777713]

Fujiwara Y, Minor DL Jr. X-ray crystal structure of a TRPM assembly domain reveals an antiparallel four-stranded coiled-coil. J Mol Biol. 2008; 383(4):854-870. DOI: 10.1016/j.jmb.2008.08.059 [PubMed: 18782578]

Gao X, Wu L, O'Neil RG. Temperature-modulated diversity of TRPV4 channel gating: activation by physical stresses and phorbol ester derivatives through protein kinase C-dependent and independent pathways. J Biol Chem. 2003; 278(29):27129-27137. DOI: 10.1074/jbc.M302517200 [PubMed: 12738791]

Gao Y, Cao E, Julius D, Cheng Y. TRPV1 structures in nanodiscs reveal mechanisms of ligand and lipid action. Nature. 2016; 534(7607):347-351. DOI: 10.1038/nature17964 [PubMed: 27281200] 
Garcia-Elias A, Mrkonjic S, Jung C, Pardo-Pastor C, Vicente R, Valverde MA. The TRPV4 channel. Handb Exp Pharmacol. 2014; 222:293-319. DOI: 10.1007/978-3-642-54215-2_12 [PubMed: 24756711]

Giamarchi A, Padilla F, Coste B, Raoux M, Crest M, Honore E, Delmas P. The versatile nature of the calcium-permeable cation channel TRPP2. EMBO Rep. 2006; 7(8):787-793. DOI: 10.1038/ sj.embor.7400745 [PubMed: 16880824]

Grieben, M., Pike, ACW., Shintre, CA., Venturi, E., El-Ajouz, S., Tessitore, A., Shrestha, L., Mukhopadhyay, S., Mahajan, P., Chalk, R., Burgess-Brown, NA., Sitsapesan, R., Huiskonen, JT., Carpenter, EP. Structure of the polycystic kidney disease TRP channel Polycystin-2 (PC2). Nat Struct Mol Biol Adv Online Publ2016https://doi.org/10.1038/nsmb.3343; http://www.nature.com/ nsmb/journal/vaop/ncurrent/abs/nsmb.3343.html-supplementaryinformation

Grimm C, Barthmes M, Wahl-Schott C. Trpml3. Handb Exp Pharmacol. 2014; 222:659-674. DOI: 10.1007/978-3-642-54215-2_26 [PubMed: 24756725]

Guler AD, Lee H, Iida T, Shimizu I, Tominaga M, Caterina M. Heat-evoked activation of the ion channel, TRPV4. J Neurosci. 2002; 22(15):6408-6414. doi:20026679. [PubMed: 12151520]

Hashimoto A, Kambe T. Mg, $\mathrm{Zn}$ and $\mathrm{Cu}$ transport proteins: a brief overview from physiological and molecular perspectives. J Nutr Sci Vitaminol. 2015; 61(Suppl):S116-S118. DOI: 10.3177/jnsv. 61.S116 [PubMed: 26598820]

Held K, Voets T, Vriens J. TRPM3 in temperature sensing and beyond. Temperature. 2015; 2(2):201213. DOI: $10.4161 / 23328940.2014 .988524$

Hinman A, Chuang H-H, Bautista DM, Julius D. TRP channel activation by reversible covalent modification. Proc Natl Acad Sci U S A. 2006; 103(51):19564-19568. DOI: 10.1073/pnas. 0609598103 [PubMed: 17164327]

Hoenderop JG, Voets T, Hoefs S, Weidema F, Prenen J, Nilius B, Bindels RJ. Homo- and heterotetrameric architecture of the epithelial Ca2+ channels TRPV5 and TRPV6. EMBO J. 2003; 22(4):776-785. DOI: 10.1093/emboj/cdg080 [PubMed: 12574114]

Hofmann T, Chubanov V, Gudermann T, Montell C. TRPM5 Is a voltage-modulated and Ca2+activated monovalent selective cation channel. Curr Biol. 2003; 13(13):1153-1158. DOI: 10.1016/ s0960-9822(03)00431-7 [PubMed: 12842017]

Huang SM, Li X, Yu Y, Wang J, Caterina MJ. TRPV3 and TRPV4 ion channels are not major contributors to mouse heat sensation. Mol Pain. 2011; 7:37.doi: 10.1186/1744-8069-7-37 [PubMed: 21586160]

Hughes J, Ward CJ, Peral B, Aspinwall R, Clark K, San Millan JL, Gamble V, Harris PC. The polycystic kidney disease 1 (PKD1) gene encodes a novel protein with multiple cell recognition domains. Nat Genet. 1995; 10(2):151-160. DOI: 10.1038/ng0695-151 [PubMed: 7663510]

Huynh KW, Cohen MR, Chakrapani S, Holdaway HA, Stewart PL, Moiseenkova-Bell VY. Structural insight into the assembly of TRPV channels. Structure. 2014; 22(2):260-268. DOI: 10.1016/j.str. 2013.11.008 [PubMed: 24373766]

Huynh KW, Cohen MR, Jiang J, Samanta A, Lodowski DT, Zhou ZH, Moiseenkova-Bell VY. Structure of the full-length TRPV2 channel by cryo-EM. Nat Commun. 2016; 7:11130. https:// doi.org/10.1038/ncomms11130. http://www.nature.com/articles/ncomms11130-supplementaryinformation. [PubMed: 27021073]

Jaquemar D, Schenker T, Trueb B. An ankyrin-like protein with transmembrane domains is specifically lost after oncogenic transformation of human fibroblasts. J Biol Chem. 1999; 274(11):7325-7333. [PubMed: 10066796]

Jordt SE, Bautista DM, Chuang HH, McKemy DD, Zygmunt PM, Hogestatt ED, Meng ID, Julius D. Mustard oils and cannabinoids excite sensory nerve fibres through the TRP channel ANKTM1. Nature. 2004; 427(6971):260-265. DOI: 10.1038/nature02282 [PubMed: 14712238]

Kanzaki M, Zhang YQ, Mashima H, Li L, Shibata H, Kojima I. Translocation of a calcium-permeable cation channel induced by insulin-like growth factor-I. Nat Cell Biol. 1999; 1(3):165-170. DOI: 10.1038/11086 [PubMed: 10559903]

Karashima Y, Damann N, Prenen J, Talavera K, Segal A, Voets T, Nilius B. Bimodal action of menthol on the transient receptor potential channel TRPA1. J Neurosci Off J Soc Neurosci. 2007; 27(37): 9874-9884. DOI: 10.1523/jneurosci.2221-07.2007 
Kohler R, Heyken WT, Heinau P, Schubert R, Si H, Kacik M, Busch C, Grgic I, Maier T, Hoyer J. Evidence for a functional role of endothelial transient receptor potential V4 in shear stress-induced vasodilatation. Arterioscler Thromb Vasc Biol. 2006; 26(7):1495-1502. DOI: 10.1161/01.ATV. 0000225698.36212.6a [PubMed: 16675722]

Komiya Y, Runnels LW. TRPM channels and magnesium in early embryonic development. Int J Dev Biol. 2015; 59(7-9):281-288. DOI: 10.1387/ijdb.1501961r [PubMed: 26679946]

Kraft R, Harteneck C. The mammalian melastatin-related transient receptor potential cation channels: an overview. Pflugers Arch - Eur J Physiol. 2005; 451(1):204-211. DOI: 10.1007/ s00424-005-1428-0 [PubMed: 15895246]

Li M, Jiang J, Yue L. Functional characterization of homo- and heteromeric channel kinases TRPM6 and TRPM7. J Gen Physiol. 2006; 127(5):525-537. DOI: 10.1085/jgp.200609502 [PubMed: 16636202]

Liao M, Cao E, Julius D, Cheng Y. Structure of the TRPV1 ion channel determined by electron cryomicroscopy. Nature. 2013; 504(7478):107-112. DOI: 10.1038/nature12822 [PubMed: 24305160]

Liedtke W, Friedman JM. Abnormal osmotic regulation in trpv4-/- mice. Proc Natl Acad Sci U S A. 2003; 100(23):13698-13703. DOI: 10.1073/pnas.1735416100 [PubMed: 14581612]

Liedtke W, Choe Y, Martí-Renom MA, Bell AM, Denis CS, Šali A, Hudspeth AJ, Friedman JM, Heller S. Vanilloid receptor-related osmotically activated channel (VR-OAC), a candidate vertebrate osmoreceptor. Cell. 2000; 103(3):525-535. DOI: 10.1016/S0092-8674(00)00143-4 [PubMed: 11081638]

Liman ER. TRPM5 and taste transduction. Handb Exp Pharmacol. 2007; 179:287-298. DOI: 10.1007/978-3-540-34891-7_17

Lishko PV, Procko E, Jin X, Phelps CB, Gaudet R. The ankyrin repeats of TRPV1 bind multiple ligands and modulate channel sensitivity. Neuron. 2007; 54(6):905-918. DOI: 10.1016/j.neuron. 2007.05.027 [PubMed: 17582331]

Liu Z, Wu H, Wei Z, Wang X, Shen P, Wang S, Wang A, Chen W, Lu Y. TRPM8: a potential target for cancer treatment. J Cancer Res Clin Oncol. 2016; 142(9):1871-1881. DOI: 10.1007/ s00432-015-2112-1 [PubMed: 26803314]

Lu W, Peissel B, Babakhanlou H, Pavlova A, Geng L, Fan X, Larson C, Brent G, Zhou J. Perinatal lethality with kidney and pancreas defects in mice with a targetted Pkd1 mutation. Nat Genet. 1997; 17(2):179-181. DOI: 10.1038/ng1097-179 [PubMed: 9326937]

Macpherson LJ, Dubin AE, Evans MJ, Marr F, Schultz PG, Cravatt BF, Patapoutian A. Noxious compounds activate TRPA1 ion channels through covalent modification of cysteines. Nature. 2007; 445(7127):541-545. http://www.nature.com/nature/journal/v445/n7127/suppinfo/ nature05544_S1.html. [PubMed: 17237762]

Malhas AN, Abuknesha RA, Price RG. Interaction of the leucine-rich repeats of polycystin-1 with extracellular matrix proteins: possible role in cell proliferation. J Am Soc Nephrol. 2002; 13(1): 19-26. [PubMed: 11752017]

McKemy, D. TRP ion channel function in sensory transduction and cellular signaling cascadesCRC Press/Taylor \& Francis; Boca Raton: 2007TRPM8: the cold and menthol receptor.

McKemy DD, Neuhausser WM, Julius D. Identification of a cold receptor reveals a general role for TRP channels in thermosensation. Nature. 2002; 416(6876):52-58. http://www.nature.com/nature/ journal/v416/n6876/suppinfo/nature719_S1.html. [PubMed: 11882888]

Mochizuki T, Wu G, Hayashi T, Xenophontos SL, Veldhuisen B, Saris JJ, Reynolds DM, Cai Y, Gabow PA, Pierides A, Kimberling WJ, Breuning MH, Deltas CC, Peters DJ, Somlo S. PKD2, a gene for polycystic kidney disease that encodes an integral membrane protein. Science. 1996; 272(5266):1339-1342. [PubMed: 8650545]

Moiseenkova-Bell VY, Stanciu LA, Serysheva II, Tobe BJ, Wensel TG. Structure of TRPV1 channel revealed by electron cryomicroscopy. Proc Natl Acad Sci U S A. 2008; 105(21):7451-7455. DOI: 10.1073/pnas.0711835105 [PubMed: 18490661]

Moqrich A, Hwang SW, Earley TJ, Petrus MJ, Murray AN, Spencer KS, Andahazy M, Story GM, Patapoutian A. Impaired thermosensation in mice lacking TRPV3, a heat and camphor sensor in the skin. Science (New York, NY). 2005; 307(5714):1468-1472. DOI: 10.1126/science.1108609 
Nilius B, Owsianik G, Voets T, Peters JA. Transient receptor potential cation channels in disease. Physiol Rev. 2007; 87(1):165-217. DOI: 10.1152/physrev.00021.2006 [PubMed: 17237345]

Nilius B, Appendino G, Owsianik G. The transient receptor potential channel TRPA1: from gene to pathophysiology. Pflugers Arch - Eur J Physiol. 2012; 464(5):425-458. DOI: 10.1007/ s00424-012-1158-z [PubMed: 23001121]

Noben-Trauth, K. The TRPML3 channel: from gene to function. In: Islam, MS., editorTransient receptor potential channelsSpringer Netherlands: Dordrecht; 2011229-237

Ong HL, de Souza LB, Ambudkar IS. Role of TRPC channels in store-operated calcium entry. Adv Exp Med Biol. 2016; 898:87-109. DOI: 10.1007/978-3-319-26974-0_5 [PubMed: 27161226]

Park U, Vastani N, Guan Y, Raja SN, Koltzenburg M, Caterina MJ. TRP vanilloid 2 knock-out mice are susceptible to perinatal lethality but display normal thermal and mechanical nociception. $\mathrm{J}$ Neurosci. 2011; 31(32):11425-11436. DOI: 10.1523/jneurosci.1384-09.2011 [PubMed: 21832173]

Paulsen CE, Armache JP, Gao Y, Cheng Y, Julius D. Structure of the TRPA1 ion channel suggests regulatory mechanisms. Nature. 2015; 520(7548):511-517. DOI: 10.1038/nature14367 [PubMed: 25855297]

Peier AM, Moqrich A, Hergarden AC, Reeve AJ, Andersson DA, Story GM, Earley TJ, Dragoni I, McIntyre P, Bevan S, Patapoutian A. A TRP channel that senses cold stimuli and menthol. Cell. 2002; 108(5):705-715. [PubMed: 11893340]

Putney JW Jr. The enigmatic TRPCs: multifunctional cation channels. Trends Cell Biol. 2004; 14(6): 282-286. DOI: 10.1016/j.tcb.2004.04.002 [PubMed: 15183184]

Qian F, Boletta A, Bhunia AK, Xu H, Liu L, Ahrabi AK, Watnick TJ, Zhou F, Germino GG. Cleavage of polycystin-1 requires the receptor for egg jelly domain and is disrupted by human autosomaldominant polycystic kidney disease 1-associated mutations. Proc Natl Acad Sci U S A. 2002; 99(26):16981-16986. DOI: 10.1073/pnas.252484899 [PubMed: 12482949]

Saotome K, Singh AK, Yelshanskaya MV, Sobolevsky AI. Crystal structure of the epithelial calcium channel TRPV6. Nature. 2016; 534(7608):506-511. DOI: 10.1038/nature17975 [PubMed: 27296226]

Shen PS, Yang X, DeCaen PG, Liu X, Bulkley D, Clapham DE, Cao E. The structure of the polycystic kidney disease channel PKD2 in lipid nanodiscs. Cell. 2016; 167(3):763-773.e711. DOI: 10.1016/ j.cell.2016.09.048 [PubMed: 27768895]

Smith GD, Gunthorpe MJ, Kelsell RE, Hayes PD, Reilly P, Facer P, Wright JE, Jerman JC, Walhin JP, Ooi L, Egerton J, Charles KJ, Smart D, Randall AD, Anand P, Davis JB. TRPV3 is a temperaturesensitive vanilloid receptor-like protein. Nature. 2002; 418(6894):186-190. DOI: 10.1038/ nature00894 [PubMed: 12077606]

Story GM, Peier AM, Reeve AJ, Eid SR, Mosbacher J, Hricik TR, Earley TJ, Hergarden AC, Andersson DA, Hwang SW, McIntyre P, Jegla T, Bevan S, Patapoutian A. ANKTM1, a TRP-like channel expressed in nociceptive neurons, is activated by cold temperatures. Cell. 2003; 112(6): 819-829. [PubMed: 12654248]

Strotmann R, Harteneck C, Nunnenmacher K, Schultz G, Plant TD. OTRPC4, a nonselective cation channel that confers sensitivity to extracellular osmolarity. Nat Cell Biol. 2000; 2(10):695-702. DOI: 10.1038/35036318 [PubMed: 11025659]

Svobodova B, Groschner K. Reprint of "Mechanisms of lipid regulation and lipid gating in TRPC channels”. Cell Calcium. 2016; 60(2):133-141. DOI: 10.1016/j.ceca.2016.06.010 [PubMed: 27431463]

Takahashi N, Mori Y. TRP channels as sensors and signal integrators of redox status changes. Front Pharmacol. 2011; 2:58.doi: 10.3389/fphar.2011.00058 [PubMed: 22016736]

Takahashi N, Kuwaki T, Kiyonaka S, Numata T, Kozai D, Mizuno Y, Yamamoto S, Naito S, Knevels E, Carmeliet P, Oga T, Kaneko S, Suga S, Nokami T, Yoshida J-I, Mori Y. TRPA1 underlies a sensing mechanism for O2. Nat Chem Biol. 2011; 7(10):701-711. doi:http://www.nature.com/ nchembio/journal/v7/n10/abs/nchembio.640.html - supplementary-information. [PubMed: 21873995] 
Tsavaler L, Shapero MH, Morkowski S, Laus R. Trp-p8, a novel prostate-specific gene, is up-regulated in prostate cancer and other malignancies and shares high homology with transient receptor potential calcium channel proteins. Cancer Res. 2001; 61(9):3760-3769. [PubMed: 11325849]

Tsiokas L, Arnould T, Zhu C, Kim E, Walz G, Sukhatme VP. Specific association of the gene product of PKD2 with the TRPC1 channel. Proc Natl Acad Sci U S A. 1999; 96(7):3934-3939. [PubMed: 10097141]

Vazquez G, Wedel BJ, Aziz O, Trebak M, Putney JW Jr. The mammalian TRPC cation channels. Biochim Biophys Acta. 2004; 1742(1-3):21-36. DOI: 10.1016/j.bbamcr.2004.08.015 [PubMed: 15590053]

Veldhuisen B, Spruit L, Dauwerse HG, Breuning MH, Peters DJ. Genes homologous to the autosomal dominant polycystic kidney disease genes (PKD1 and PKD2). Eur J Hum Genet. 1999; 7(8):860872. DOI: 10.1038/sj.ejhg.5200383 [PubMed: 10602361]

Venkatachalam K, Montell C. TRP channels. Annu Rev Biochem. 2007; 76:387-417. DOI: 10.1146/ annurev.biochem.75.103004.142819 [PubMed: 17579562]

Venkatachalam K, Wong CO, Zhu MX. The role of TRPMLs in endolysosomal trafficking and function. Cell Calcium. 2015; 58(1):48-56. DOI: 10.1016/j.ceca.2014.10.008 [PubMed: 25465891]

Voltz JW, Weinman EJ, Shenolikar S. Expanding the role of NHERF, a PDZ-domain containing protein adapter, to growth regulation. Oncogene. 2001; 20(44):6309-6314. DOI: 10.1038/sj.onc. 1204774 [PubMed: 11607833]

Wang W, Zhang X, Gao Q, Xu H. TRPML1: an ion channel in the lysosome. Handb Exp Pharmacol. 2014; 222:631-645. DOI: 10.1007/978-3-642-54215-2_24 [PubMed: 24756723]

Wes PD, Chevesich J, Jeromin A, Rosenberg C, Stetten G, Montell C. TRPC1, a human homolog of a drosophila store-operated channel. Proc Natl Acad Sci U S A. 1995; 92(21):9652-9656. [PubMed: 7568191]

Wilson PD. Polycystin: new aspects of structure, function, and regulation. J Am Soc Nephrol. 2001; 12(4):834-845. [PubMed: 11274246]

Wu L, Gao X, Brown RC, Heller S, O’Neil RG. Dual role of the TRPV4 channel as a sensor of flow and osmolality in renal epithelial cells. Am J Physiol Ren Physiol. 2007; 293(5):F1699-F1713. DOI: 10.1152/ajprenal.00462.2006

Xu H, Ramsey IS, Kotecha SA, Moran MM, Chong JA, Lawson D, Ge P, Lilly J, Silos-Santiago I, Xie Y, DiStefano PS, Curtis R, Clapham DE. TRPV3 is a calcium-permeable temperature-sensitive cation channel. Nature. 2002; 418(6894):181-186. DOI: 10.1038/nature00882 [PubMed: 12077604]

Zholos A, Johnson C, Burdyga T, Melanaphy D. TRPM channels in the vasculature. Adv Exp Med Biol. 2011; 704:707-729. DOI: 10.1007/978-94-007-0265-3_37 [PubMed: 21290323]

Zubcevic L, Herzik MA Jr, Chung BC, Liu Z, Lander GC, Lee SY. Cryo-electron microscopy structure of the TRPV2 ion channel. Nat Struct Mol Biol. 2016; 23(2):180-186. DOI: 10.1038/nsmb.3159 [PubMed: 26779611]

Zygmunt PM, Hogestatt ED. TRPA1. Handb Exp Pharmacol. 2014; 222:583-630. DOI: 10.1007/978-3-642-54215-2_23 [PubMed: 24756722] 


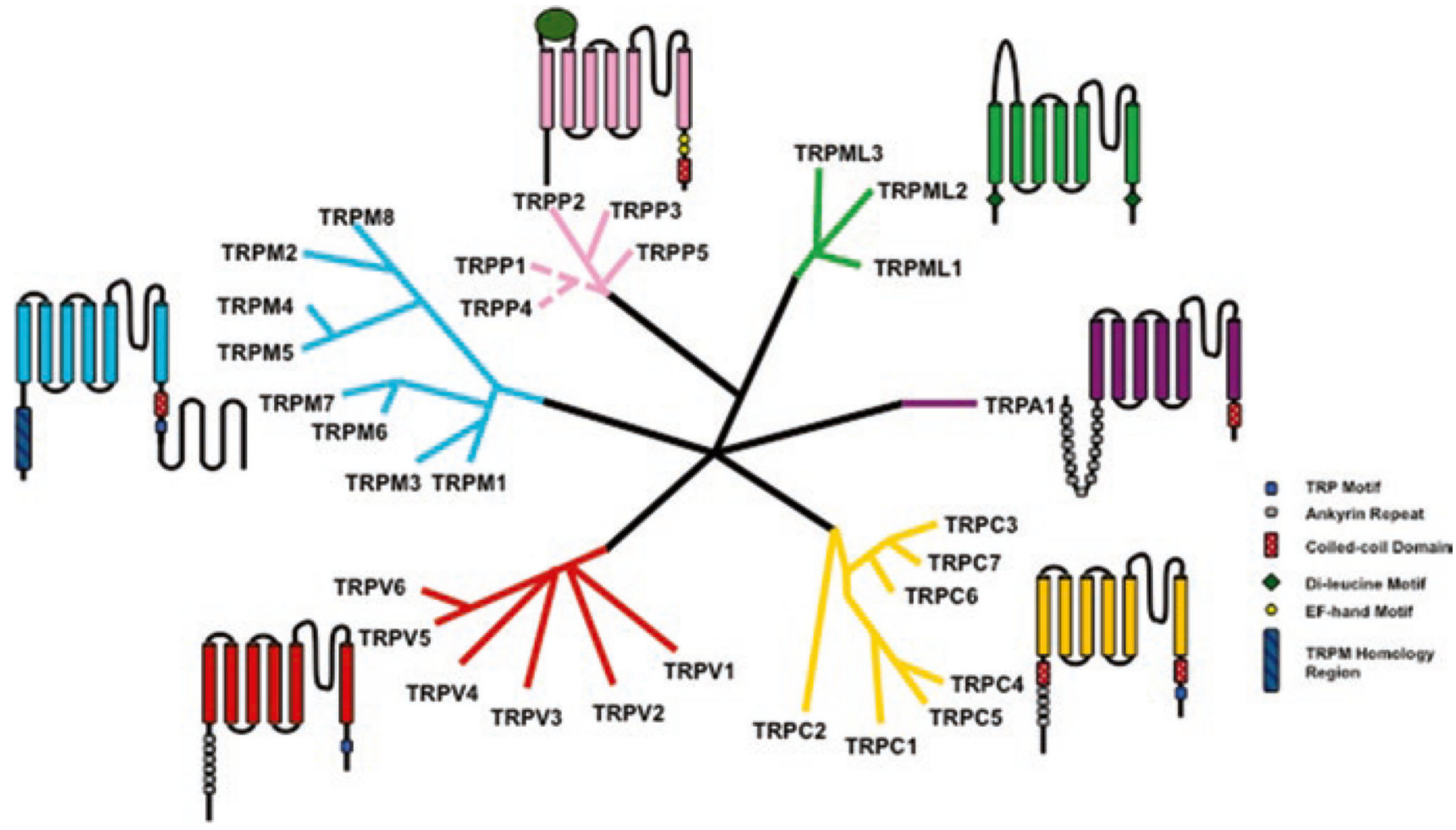

Fig. 6.1.

A schematic representation of the TRP superfamily of ion channels. Each branching group is representative of a subfamily of channels 
A



Minimal TRPV1 in amphipol at $3.4 \mathrm{~A}$ fesolution

B

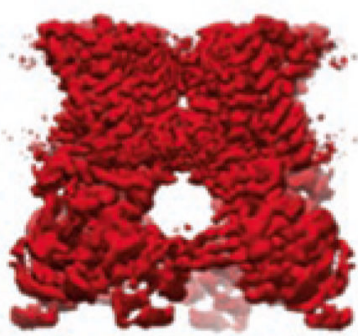

Minimal TRPV1 in nanodisc at $3.28 \mathrm{~A}$ resolution c

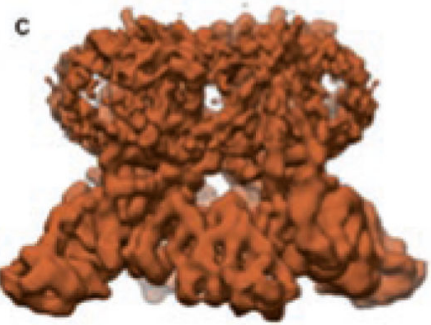

Full length TRPV2 at 4.4A resolution

D

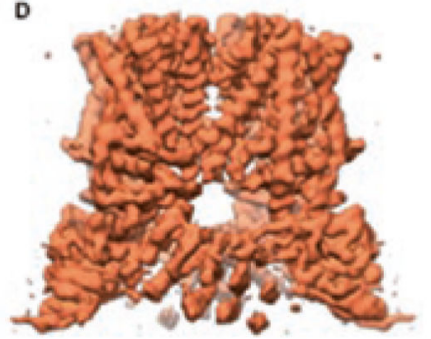

Minimal TREV 2 in amphipol at $3.8 \mathrm{~A}$ resolution

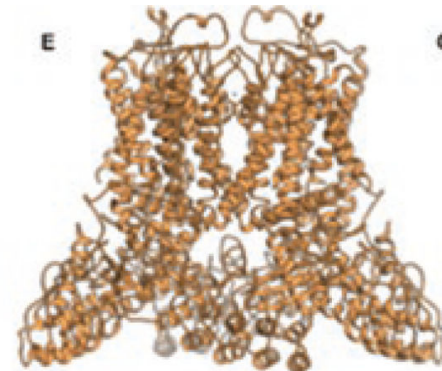

THEW6, at $3.2 \mathrm{~A}$ resolution

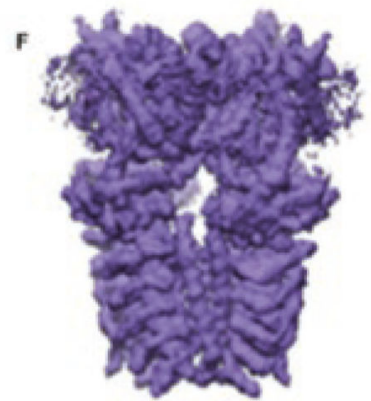

TRPA1 at $4.24 . \bar{A}$ resolution

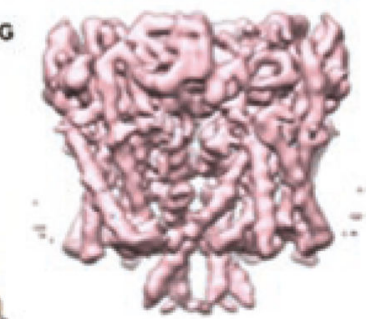

Minimal TRpP2 at $4.2 \mathrm{~A}$ resolution

H

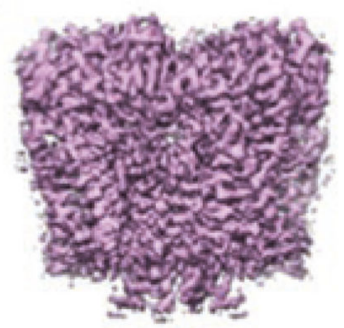

Minimal TRPP2 in anphipol at $3 \mathrm{~A}$ resolution

Fig. 6.2.

Select high resolution structures of TRP channels. (a) and (b) Cryo-EM density maps of TRPV1 (Liao et al. 2013; Gao et al. 2016). (c) and (d) Cryo-EM density maps of TRPV2 (Huynh et al. 2016; Zubcevic et al. 2016). (e) X-ray crystal structure of TRPV6 (Saotome et al. 2016). (f) Cryo-EM density map of TRPA1 (Paulsen et al. 2015). (g) and (h) Cryo-EM density maps of TRPP2 (Grieben et al. 2016; Shen et al. 2016) 


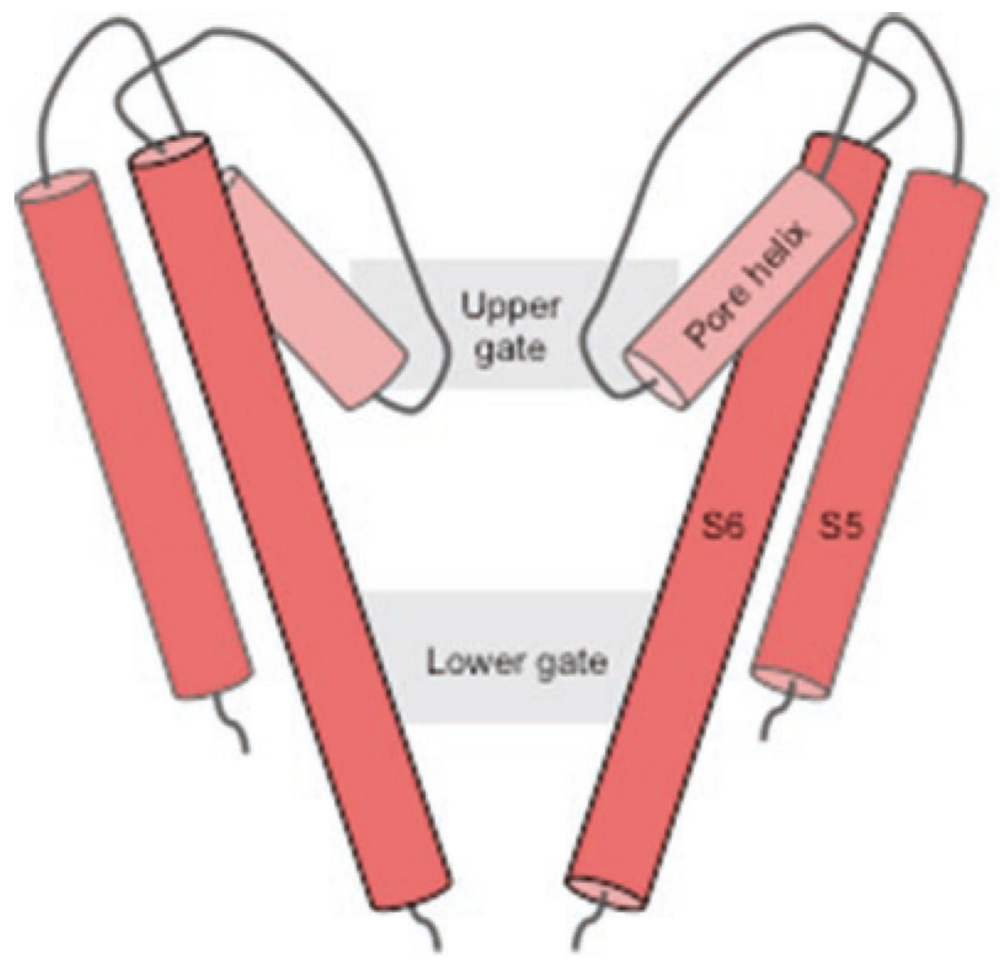

\begin{tabular}{|c|c|c|}
\hline $\begin{array}{l}\text { TRP } \\
\text { protein }\end{array}$ & Upper Gate & Lower Gate \\
\hline TRPV1 & $\begin{array}{l}\text { Gyb643 and } \\
\text { Mete44 }\end{array}$ & Ie679 \\
\hline TRPV2 & $\begin{array}{l}\text { Gye604 and } \\
\text { Met605 }\end{array}$ & Mev643 \\
\hline TRPVS & Asps4 1 & 1200577 \\
\hline TRPA1 & Asp915 & $\begin{array}{l}\text { Ie957 and } \\
\text { Vas61 }\end{array}$ \\
\hline TRPP2 & $\begin{array}{l}\text { lis641, Gly642 } \\
\text { and Aspes43 }\end{array}$ & $\begin{array}{c}\text { Leu677 and } \\
\text { Asnssi }\end{array}$ \\
\hline
\end{tabular}

Fig. 6.3.

A schematic representation of the the TRP channel pore showing the two regions of constriction (gates). The residues forming the two gates in various TRP proteins are listed in the Table on the right 


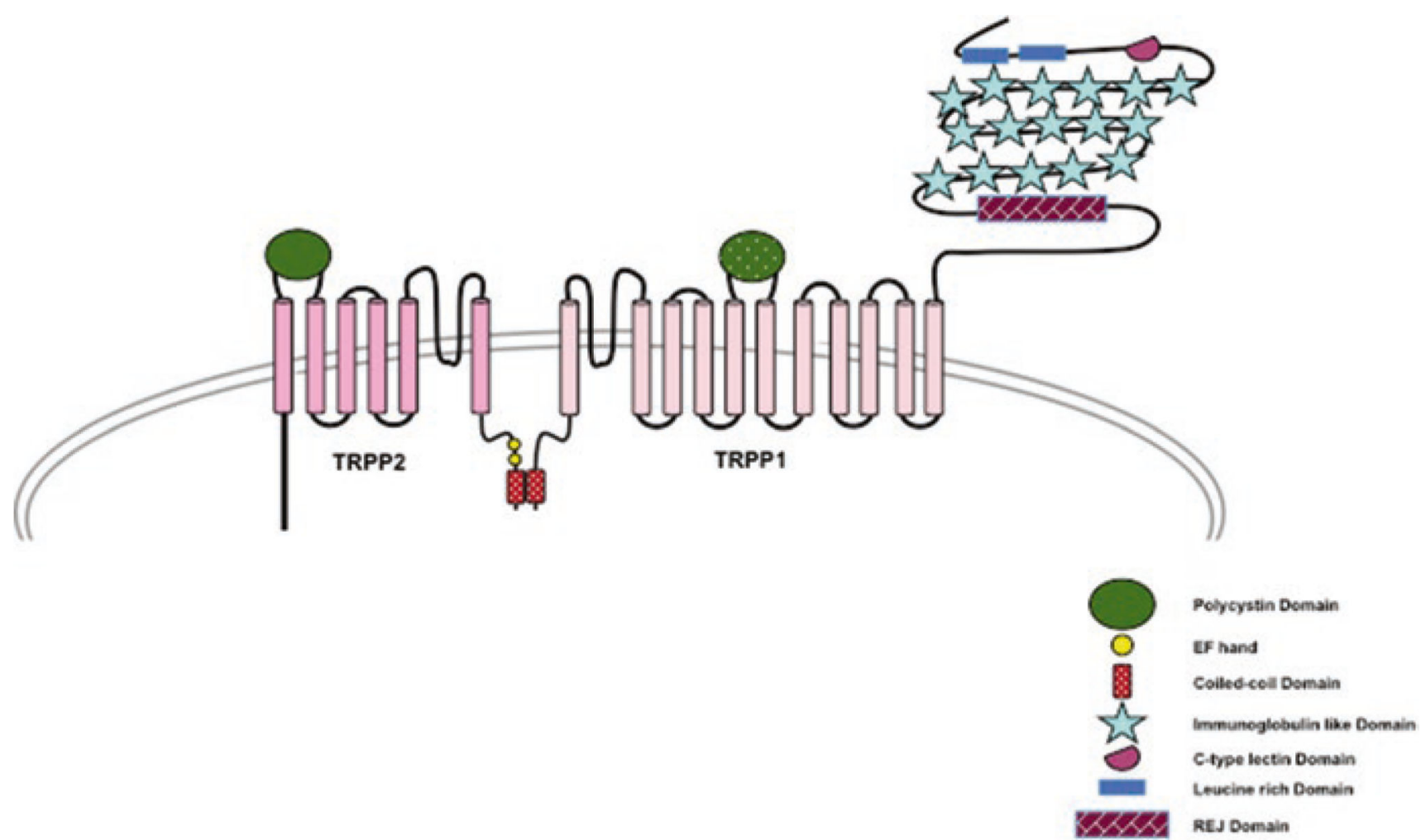

Fig. 6.4.

A schematic representation of TRPP1 and TRPP2 interacting with each other through their $\mathrm{C}$-terminal region and forming the receptor-channel complex 